\title{
Perfluoroalkyl and polyfluoroalkyl substances in sediments from South Bohai coastal watersheds, China
}

\author{
Zhaoyun Zhu ${ }^{\mathrm{a}, \mathrm{b}}$, Tieyu Wang ${ }^{\mathrm{a}, *}$, Pei Wang ${ }^{\mathrm{a}, \mathrm{b}}$, Yonglong Lu ${ }^{\mathrm{a}}$, John P. Giesy ${ }^{\mathrm{c}}$ \\ a State Key Lab of Urban and Regional Ecology, Research Center for Eco-Environmental Sciences, Chinese Academy of Sciences, Beijing 100085, China \\ ${ }^{\mathrm{b}}$ Graduate University of Chinese Academy of Sciences, Beijing 100049, China \\ ${ }^{\mathrm{c}}$ Department of Veterinary Biomedical Sciences and Toxicology Centre, University of Saskatchewan, Saskatoon, Saskatchewan, Canada
}

\section{A R T I C L E I N F O}

Article history:

Available online 8 January 2014

\section{Keywords:}

PFAS

Sediment

Partitioning

Hazard assessment

South Bohai

\begin{abstract}
A B S T R A C T
This study investigated the concentrations and distribution of Perfluoroalkyl and polyfluoroalkyl substances (PFAS) in sediments of 12 rivers from South Bohai coastal watersheds. The highest concentrations of $\Sigma$ PFAS (31.920 $\mathrm{ng} \mathrm{g}^{-1} \mathrm{dw}$ ) and PFOA (29.021 $\mathrm{ng} \mathrm{g}^{-1} \mathrm{dw}$ ) were found in sediments from the Xiaoqing River, which was indicative of local point sources in this region. As for other rivers, concentrations of ¿PFAS ranged from 0.218 to $1.583 \mathrm{ng} \mathrm{g}^{-1} \mathrm{dw}$ were found in the coastal sediments and from 0.167 to $1.953 \mathrm{ng} \mathrm{g}^{-1} \mathrm{dw}$ in the riverine sediments. Predominant PFAS from coastal and riverine areas were PFOA and PFBS, with percentages of 30\% and 35\%, respectively. Partitioning analysis showed the concentrations of PFNA, PFDA and PFHxS were significantly correlated with organic carbon. The results of a preliminary environmental hazard assessment showed that PFOS posed the highest hazard in the Mi River, while PFOA posed a relative higher hazard in the Xiaoqing River.
\end{abstract}

(c) 2013 Elsevier Ltd. All rights reserved.

\section{Introduction}

Perfluoroalkyl and polyfluoroalkyl substances (PFAS) such as perfluorocarboxylates (PFCAs) and perfluoroalkanesulfonates (PFSAs), which have been produced for more than 50 years, have emerged as a new class of global environmental pollutants since they were first reported to be widespread in the environment (Giesy and Kannan, 2001, 2002; 3M Company, 1999). The unique physicochemical properties of PFAS, such as high surface activity, thermal stability, amphiphilicity, resistance to acidic and alkaline conditions and weak intermolecular interactions, make them popular in many industrial applications (e.g., fire-fighting foams, photolithography, and pesticides) and consumer applications (e.g., shampoos, surface coatings for carpets, stain repellents for furniture, and paper products) (Kissa, 2001; Giesy and Kannan, 2001; Higgins et al., 2005; Paul et al., 2008). PFAS can be released into the environment through their production and usage. The strong $\mathrm{C}-\mathrm{F}$ bond of PFAS makes them extremely resistant to hydrolysis, thermal, microbiological and photolytical degradation (Wang et al., 2009). PFAS are ubiquitous in river water, oceans, sediment, soil, and tissues of wildlife and humans (Ahrens et al., 2010a; Higgins et al., 2005;Wang et al., 2013; Giesy and Kannan, 2001; Bao et al., 2010a; Kannan et al., 2001, 2002a,b). They are potentially harmful to fresh water and marine mammals (Ishibashi et al., 2008) and have potential adverse effects in wildlife species (Hoff

\footnotetext{
* Corresponding author. Tel.: +86 1062849466 .

E-mail address: wangty@rcees.ac.cn (T. Wang).
}

et al., 2005; Fair et al., 2012; Beach et al., 2005; Newsted et al., 2005, 2008; Giesy et al., 2009).

Sediment is an important sink and reservoir of persistent organic pollutants and has a large impact on their distribution, transportation, and fate in the aquatic environment (Ahrens et al., 2009; Yang et al., 2011). Some researchers reported that the only environmental sink for perfluorooctanoate (PFO, refers to PFOA \& PFOS) was sediment burial and transport to the deep oceans (Prevedouros et al., 2006). The distribution of PFAS between water and sediment is considered as an important process which controls their transport and fate (Prevedouros et al., 2006; You et al., 2010). Sediment-water distribution is a complex process, depending not only on the physicochemical characteristics of the compounds but also on the sediment nature such as the organic carbon fraction $\left(f_{o c}\right)$ (Ahrens et al., 2010b; Zhao et al., 2012). Sorption of PFAS on sediment has been studied under laboratory conditions (Higgins and Luthy, 2006), but there are few field studies focused on partitioning behavior of PFAS in aquatic environments (Ahrens et al., 2009; Zhang et al., 2012; Zhao et al., 2013). Results of studies under laboratory conditions and those observed in the field can be different (Hong et al., 2013). To gain better understanding on the fate of PFAS in the whole environment, more information of field study is necessary on partitioning behavior of PFAS.

The Bohai Sea region in north China is an area where industry has been developing rapidly during the past few decades. The Bohai Sea, a semi-enclosed coastal water body with almost 40 rivers flowing directly into it, receives enormous amounts of 
contaminants through discharge of river water and sediment. The Bohai Sea region is currently one of the most polluted areas in China due to the industrial and agricultural activities (Hu et al., 2010; Luo et al., 2010; Naile et al., 2010; Zhao et al., 2013). Occurrence, spatial distribution, source and fate of PFAS in different matrices in estuarine and coastal areas of North Bohai Sea had been studied previously (Wang et al., 2011). Results of another study in the coastal area of Liao Dong Bay revealed that direct emission from industry parks was a major source of PFAS in soil (Wang et al., 2013). However, there are limited reports about PFAS in the southern part of the coast of the Bohai Sea compared with the northern part. Concentrations and distribution of PFAS in surface sediments from Laizhou Bay and its adjacent rivers have been measured and from that it was learned that concentrations of PFOA were extremely high in that area and might pose a potential threat for the benthic organisms (Zhao et al., 2013).

Currently, there is limited information about PFAS in sediments of coastal rivers along the South Bohai coast. The present study, launched in 2008, was conducted as a systematic investigation to trace sources and fates of toxic substances in various environmental media from adjacent riverine and estuarine areas including the Yellow and Bohai Seas of China. The specific objectives of this study were to: (1) determine concentrations and spatial distribution of PFAS in sediments from coastal rivers along the south coast of the Bohai Sea; (2) identify potential sources of PFAS; and (3) conduct a screening-level ecological hazard assessment for PFAS in local aquatic ecosystems. The results of the study provide information and support for future determinations of status and trends of PFAS emissions and their management at regional and national levels.

\section{Materials and methods}

\subsection{Standards and reagents}

17 kinds of PFAS standards, including perfluorobutanoic acid (PFBA), perfluoropentanoic acid (PFPeA), perfluorohexanoic acid (PFHxA), perfluoroheptanoic acid (PFHpA), perfluorooctanoic acid (PFOA), perfluorononanoic acid (PFNA), perfluorodecanoic acid (PFDA), perfluoroundecanoic acid (PFUdA), perfluorododecanoic acid (PFDoA), perfluorotridecanoic acid (PFTrDA), perfluorotetradecanoic acid (PFTeDA), perfluorohexadecanoic acid (PFHxDA), perfluorooctadecanoic acid (PFODA), potassium perfluorobutanesulfonate (PFBS), sodium perfluorohexanesulfonate (PFHXS), potassium perfluorooctanesulfonate (PFOS), sodium perfluorodecanesulfonate (PFDS), and 5 mass-labeled internal standards, including PFBA $\left[1,2,3,4{ }^{13} \mathrm{C}\right]$, PFOA $\left[1,2,3,4{ }^{13} \mathrm{C}\right]$, PFDoA $\left[1,2{ }^{13} \mathrm{C}\right]$, PFHxS $\left[1,2{ }^{18} \mathrm{O}\right]$ and PFOS $\left[1,2,3,4{ }^{13} \mathrm{C}\right]$, were obtained from Wellington Laboratories with purities of $>98 \%$ (Guelph, Ontario, Canada). The mixed standards were prepared in $100 \%$ methanol and stored at $4{ }^{\circ} \mathrm{C}$. HPLC grade methanol, acetonitrile and methyl tert-butyl ether (MTBE) were purchased from J.T. Baker (Phillipsburg, NJ, USA). Ammonium acetate, anhydrous sodium sulfate and tetrabutylammonium hydrogensulfate (TBAHS) were purchased from Sigma-Aldrich Co. (St. Louis, MO, USA). Milli-Q water was obtained from a Milli-Q synthesis A10 (Millipore, Bedford, MA, USA) and used throughout the experiment.

\subsection{Sediment sampling}

A total of 36 surface (top 1-5 cm) samples of sediment were collected from 12 typical coastal rivers, which flow into the Bohai Sea through Shandong and Hebei Provinces (Fig. 1). For each river, at least 2 sites were chosen with the first one near the coast and the other a distance of $20-30 \mathrm{~km}$ from the former. All surface sam- ples were collected in September 2011 by use of a clean, stainless steel trowel, and placed in clean $250 \mathrm{~mL}$, largemouth, and polypropylene (PP) bottles. Wet sediments were immediately transported to the laboratory in ice-cooled boxes and then dried in a FreeZone 2.5 Liter Benchtop Freeze Dry System (LABCONCO, Kansas City, $\mathrm{MO})$, ground and homogenized with a silica mortar and pestle, sieved through a $2-\mathrm{mm}$ mesh, and stored in pre-cleaned glass jars in room temperature until further analysis.

\subsection{Sample extraction and instrumental analysis}

Detection of PFAS: Sediments were extracted according to a previously published method with minor modifications and optimizations (Naile et al., 2010; Wang et al., 2013). Briefly, a $50 \mathrm{ml}$ polypropylene centrifuge tube was charged with $2.5 \mathrm{~g}$ homogenized sediments, which were soaked with $2 \mathrm{~mL}$ Milli-Q water and vortexed until the samples were visually homogenized. A $1 \mathrm{~mL}$ portion of $0.5 \mathrm{M}$ tetrabutylammonium hydrogensulfate (TBAHS) and $2 \mathrm{~mL}$ of $25 \mathrm{mM}$ sodium acetate were added, and spiked with $10 \mathrm{ng}$ mass-labeled internal standards with vortexing. Subsequently, $5 \mathrm{~mL}$ of methyl tert-butyl ether (MTBE) was added and the mixture was extracted 20 min by vibration and then centrifuged at $3500 \mathrm{rpm}$ for $30 \mathrm{~min}$. This process of extraction with MTBE was repeated three times and the upper MTBE fraction was combined together into a $15 \mathrm{~mL}$ PP tube. The eluate was then evaporated to dryness under a gentle flow of high purity nitrogen, and reconstituted in $1 \mathrm{~mL}$ methanol, then filtered through a $0.2 \mathrm{~mm}$ nylon filter, transferred into a $1.5 \mathrm{~mL}$ PP snap top brown glass vial with polyethylene (PE) septa for HPLC analysis. The instrumental analysis was performed using a high performance liquid chromatography-negative electrospray ionization-tandem mass spectrometry system (HPLC-ESI-MS/MS) that consisted of an Agilent 1290 Infinity HPLC System coupled to an Agilent 6460 Triple Quadrupole LC/MS System (Agilent Technologies, Palo Alto, CA). The instrument conditions are listed in Table S1.

Detection of organic carbon fraction $\left(f_{o c}\right)$ : The procedure used is based on a wet digestion method without heating followed by colorimetric determination (Chatterjee et al., 2009; Da Silva Dias et al., 2012). Briefly, a $0.5 \mathrm{~g}$ sediment sample was placed in a $100 \mathrm{~mL}$ Erlenmeyer flask, then $10 \mathrm{~mL}$ of potassium dichromate solution $\left(0.667 \mathrm{~mol} \mathrm{~L}^{-1}\right)$ and $10 \mathrm{~mL}$ of sulfuric acid were added. Flasks were swirled for $5 \mathrm{~min}$ to homogenize the mixture. After reacting for $20 \mathrm{~min}$ and standing for $1 \mathrm{~h}$ to cool, $10 \mathrm{~mL}$ Milli-Q water was added to the flasks. After standing overnight $(12 \mathrm{~h})$, $15 \mathrm{~mL}$ supernatant solution was taken out and diluted to $50 \mathrm{~mL}$ by adding Milli-Q water. Then the solution was measured by a UV spectrophotometer under the light transmittance at $590-\mathrm{nm}$ wavelength.

\subsection{Quality assurance and quality control}

All fluorinated materials that could come into contact with the samples during sampling and extraction were removed to avoid contaminations. Nine-point external standard curves ranging from 0.01 to $100 \mathrm{ng} \mathrm{mL}^{-1}$ were prepared for the quantification of individual PFAS with coefficients of determination $\left(r^{2}\right)$ for all the target analytes higher than 0.99 . The limit of detection (LOD) and limit of quantification (LOQ) were defined as the peak of analyte required to yield a signal-to-noise $(\mathrm{S} / \mathrm{N})$ ratio of 3:1 and 10:1, respectively. Recoveries of internal standards spiked into sediments ranged from $73 \%$ to $119 \%$. Concentrations of PFAS were not corrected for recoveries. Procedure blanks using anhydrous sodium sulfate as alternative of sediment were conducted with every sample set and solvent blanks using 100\% methanol were run every 4-5 samples to check for carryover and background contamination. No detectable PFAS were observed over LOQ in all the procedure and 


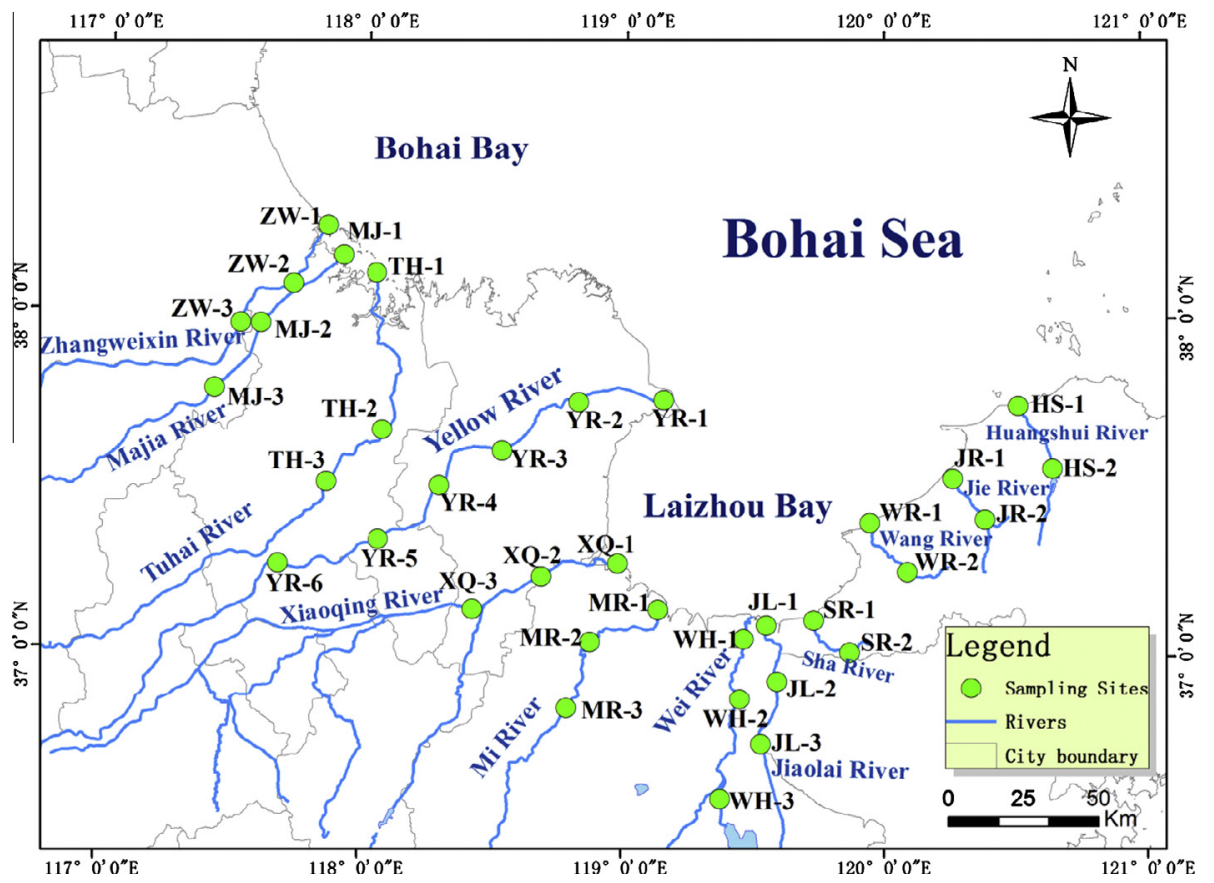

Fig. 1. Sampling positions of sediment in South Bohai coastal rivers.

solvent blanks. Detailed QA/QC measurements of PFAS in sediment are given in Table 1.

\subsection{Statistical analysis}

Statistical analysis was performed with IBM SPSS Statistics V21. Before analyzing, concentration values lower than the LOQs were set to one-half of the LOQs, and those lower than the LODs were assigned as values of the LODs $/ \sqrt{2}$ (Bao et al., 2010a). A statistical distribution test called $P-P$ plots was carried out to test for normality. Spatial distributions of PFAS were analyzed using ArcGIS V10.0 software (ESRI).

\section{Results and discussion}

\subsection{PFAS in sediments from South Bohai coastal rivers}

In sediments collected from South Bohai coastal rivers, 14 out of 17 target PFAS were quantified, including: $\mathrm{C}_{4}-\mathrm{C}_{14}$-PFCAs, and $\mathrm{C}_{4^{-}}$, $\mathrm{C}_{6^{-}}$, and $\mathrm{C}_{8^{-}}$PFSAs. Concentrations of PFAS in sediments from South Bohai coastal rivers were generally lower than the corresponding LOQs (Table S2). The total concentrations of PFAS in surface sediments ranged from $0.098 \mathrm{ng} \mathrm{g}^{-1} \mathrm{dw}$ to $1.889 \mathrm{ng} \mathrm{g}^{-1} \mathrm{dw}$ with a mean of $0.477 \mathrm{ng} \mathrm{g}^{-1} \mathrm{dw}$ (except for the Xiaoqing River). The highest concentration of $\Sigma$ PFAS (31.92 $\mathrm{ng} \mathrm{g}^{-1} \mathrm{dw}$ ) was found at the upstream location in the Xiaoqing River, and the value was approximately 2 orders of magnitude higher than the average

Table 1

Target analytes of 17 PFAS measured in this study with QA/QC information.

\begin{tabular}{|c|c|c|c|c|c|}
\hline Analyte & Acronym & MS/MS transition $(\mathrm{m} / \mathrm{z})$ & $\begin{array}{l}\text { Recovery }(n=4) \\
\% \text { Mean } \pm \text { SD }\end{array}$ & LOD $\left(\mathrm{ng} \mathrm{g}^{-1}\right)$ & $\operatorname{LOQ}\left(\mathrm{ng} \mathrm{g}^{-1}\right)$ \\
\hline Perfluorocarboxylic acid & PFCAs & & & & \\
\hline Perfluorobutanoic acid & PFBA & $213.0 \rightarrow->169.1$ & $100 \pm 5$ & 0.02 & 0.1 \\
\hline Perfluoropentanoic acid & PFPeA & $263.0 \rightarrow 218.9$ & $104 \pm 3$ & 0.01 & 0.03 \\
\hline Perfluorohexanoic acid & PFHxA & $313.0 \rightarrow 269.0$ & $110 \pm 3$ & 0.004 & 0.01 \\
\hline Perfluoroheptanoic acid & PFHpA & $363.0 \rightarrow 318.9$ & $96 \pm 6$ & 0.006 & 0.02 \\
\hline Perfluorooctanoic acid & PFOA & $413.0 \rightarrow 368.9$ & $100 \pm 11$ & 0.002 & 0.01 \\
\hline Perfluorononanoic acid & PFNA & $463.0 \rightarrow 419.0$ & $109 \pm 2$ & 0.002 & 0.01 \\
\hline Perfluorodecanoic acid & PFDA & $513.0 \rightarrow 468.9$ & $103 \pm 7$ & 0.004 & 0.01 \\
\hline Perfluoroundecanoic acid & PFUdA & $563.0 \rightarrow 519.0$ & $90 \pm 4$ & 0.008 & 0.02 \\
\hline Perfluorododecanoic acid & PFDoA & $613.0 \rightarrow 569.0$ & $89 \pm 4$ & 0.004 & 0.01 \\
\hline Perfluorotridecanoic acid & PFTrDA & $662.9 \rightarrow 619.0$ & $93 \pm 2$ & 0.006 & 0.02 \\
\hline Perfluorotetradecanoic acid & PFTeDA & $713.1 \rightarrow 669.0$ & $73 \pm 4$ & 0.006 & 0.02 \\
\hline Perfluorohexadecanoic acid & PFHxDA & $813.0 \rightarrow 769.0$ & $73 \pm 1$ & 0.006 & 0.02 \\
\hline Perfluorooctadecanoic acid & PFODA & $913.0 \rightarrow 869.0$ & $87 \pm 5$ & 0.006 & 0.02 \\
\hline Perfluorinated sulfonic acid & PFSAs & & & & \\
\hline Perfluorobutanesulfonat & PFBS & $299.0 \rightarrow 80.0$ & $119 \pm 4$ & 0.004 & 0.01 \\
\hline Perfluorohexanesulfonat & PFHxS & $399.0 \rightarrow 80.0$ & $114 \pm 8$ & 0.004 & 0.01 \\
\hline Perfluorooctanesulfonat & PFOS & $498.9 \rightarrow 80.0$ & $117 \pm 2$ & 0.004 & 0.01 \\
\hline Perfluorodecanesulfonat & PFDS & $599.0 \rightarrow 79.9$ & $86 \pm 6$ & 0.01 & 0.02 \\
\hline
\end{tabular}


concentration and 16.9 times higher than the highest concentration ( $\left.1.889 \mathrm{ng} \mathrm{g}^{-1} \mathrm{dw}\right)$ in the other 11 rivers. These high concentrations might be a result of receiving urban, industrial, and agricultural wastewater and sludge over the past decades (Zhao et al., 2013).

The summary of PFAS concentrations in the coastal and riverine sediments are shown in Table 2. PFAS in the Xiaoqing River sediments will be discussed separately because of their high concentrations compared with the other 11 coastal rivers. In this study, the concentrations of $\Sigma$ PFAS ranged from $0.218 \mathrm{ng} \mathrm{g}^{-1} \mathrm{dw}$ to $1.583 \mathrm{ng} \mathrm{g}^{-1} \mathrm{dw}$ (mean: $0.535 \mathrm{ng} \mathrm{g}^{-1} \mathrm{dw}$ ) in the coastal sediments and from $0.167 \mathrm{ng} \mathrm{g}^{-1} \mathrm{dw}$ to $1.953 \mathrm{ng} \mathrm{g}^{-1} \mathrm{dw}$ (mean: $0.578 \mathrm{ng} \mathrm{g}^{-1} \mathrm{dw}$ ) in the riverine sediments, respectively. The average concentration of $\Sigma$ PFCAs in coastal sediments $\left(0.259 \mathrm{ng} \mathrm{g}^{-1} \mathrm{dw}\right)$ was higher than that in the riverine sediments $\left(0.208 \mathrm{ng} \mathrm{g}^{-1} \mathrm{dw}\right)$, while the average concentration of $\Sigma$ PFSAs in the riverine sediments $\left(0.370 \mathrm{ng} \mathrm{g}^{-1} \mathrm{dw}\right)$ was higher than that in the coastal sediments $\left(0.276 \mathrm{ng} \mathrm{g}^{-1} \mathrm{dw}\right)$. The Xiaoqing River had the highest concentration of $\Sigma$ PFAS in both coastal and riverine sediments ( $2.756 \mathrm{ng} \mathrm{g}^{-1} \mathrm{dw}$ and $31.920 \mathrm{ng} \mathrm{g}^{-1} \mathrm{dw}$, respectively). Generally, the concentrations of $\Sigma$ PFAS in riverine sediments were higher than that those in coastal sediments.

Composition profiles of PFAS in the coastal and riverine sediments from South Bohai Bay are shown in Fig. 2. The dominant PFAS compound in the coastal sediments was PFOA, with a contribution of $30 \%$ to the total PFAS. Other major components were PFBS (29\%), PFOS (20\%), and PFBA (8\%). The situation was quite different in the riverine sediments with contribution of PFOA being only $8 \%$ while contributions of PFBS, PFOS and PFBA were $35 \%$, $27 \%$ and $15 \%$, respectively. As for the Xiaoqing River, although concentrations of PFAS varied largely at different sampling sites along the river, PFOA was the dominant PFAS in all samples with a high contribution of over $90 \%$.

\subsection{Spatial distribution and source identification}

The spatial distribution of $\Sigma$ PFAS in sediment from South Bohai coastal rivers is shown in Fig. 3. It is obvious that Xiaoqing River had the highest $\Sigma$ PFAS $\left(2.756-31.920 \mathrm{ng} \mathrm{g}^{-1} \mathrm{dw}\right)$ in this area, especially for the site XQ-3 (31.920 $\left.\mathrm{ng} \mathrm{g}^{-1} \mathrm{dw}\right)$, which was relatively far from the coastline. The Xiaoqing River, with a total length of $216 \mathrm{~km}$ and a drainage area of $10,336 \mathrm{~km}^{2}$, flows through several major cities, including Ji'nan, Zibo, Binzhou, Dongying, and Weifang in Shandong Province, China. As an important inland ship-transport river in Shandong Province and the only discharge channel of wastewater in Ji'nan city, the Xiaoqing River receives all kinds of wastewater and sludge. Although control measures like building more municipal sewage treatment plants and sewage interception facilities were carried out in recent years, there were still huge amounts of sewage and garbage pouring into the Xiaoqing River. The high concentrations of PFAS in sediments of this river might result from upstream transportation, tributaries of industrial discharge as well as local release of garbage and wastewater from human activities along the river. The relatively high concentrations of $\Sigma$ PFAS in Jiaolai River sediment (0.404$1.638 \mathrm{ng} \mathrm{g}^{-1} \mathrm{dw}$ ) might be from the upper stream historically industrial wastewater discharge, such as iron ore plants and chemical fiber factories. Site ZW-3 in Zhangwei River was found to have a higher value of $\Sigma$ PFAS (1.889 $\mathrm{ng} \mathrm{g}^{-1} \mathrm{dw}$ ) in sediment compared to other sampling sites in this river, indicating a potential point source at this site. According to the existing environmental situation of this sampling site, the most possible source might be paper manufacturing factories at south of this sampling position, since PFOS-substances derived from perfluorooctane sulfonyl fluoride (POSF) and their simple derivatives were widely used in paper treatment in China (Xie et al., 2013). Similar results were found on the estuary of both the Mi (site MR-1, $0.863 \mathrm{ng} \mathrm{g}^{-1} \mathrm{dw}$ ) and Wang Rivers (site WR-1, $1.511 \mathrm{ng} \mathrm{g}^{-1} \mathrm{dw}$ ). There was direct discharge of wastewater from a fertilizer factory and salt fields around site MR- 1 , which could be the sources of PFAS. The industry park located near site WR-1 could also be the source of PFAS. The major discharging river in this area was the Yellow River, which from 1919 to 2008 had discharged approximately $12.7 \times 10^{8} \mathrm{t} \mathrm{a}^{-1}$ sediment into the Bohai Sea (Mu et al., 2012). Comparing to its adjacent rivers, the Yellow River had lower concentrations of $\Sigma$ PFAS in sediments. One reason might be that the riverbed of the Yellow River in Shandong Province is rather high. Therefore it is unlikely to receive sewage from local facilities. The other reason might be that the water and sediment regulation conducted on the Yellow River every year since 2002 increased erosion in the downstream part of the Yellow River, carrying most of the surface sediment into the Bohai Sea (Li, 2004; Yao et al., 2009; Wang et al., 2010). The much higher discharge of the Yellow River than those of other rivers in this study would lead to more dilution, which could also be an explanation of this phenomenon. Generally speaking, concentrations of $\Sigma$ PFAS in sediment at inland riverine locations were higher than those in coastal sediment because of the scouring and dilution of tidal currents and waves, and explanations have been found for

Table 2

PFAS concentrations in sediments from South Bohai coastal rivers (ng g ${ }^{-1} \mathrm{dw}$ ).

\begin{tabular}{|c|c|c|c|c|c|c|c|c|c|c|c|}
\hline \multirow[b]{3}{*}{ PFBA } & \multicolumn{4}{|c|}{ Coastal sediment $(n=13)$} & \multicolumn{4}{|c|}{ Riverine sediment $(n=20)$} & \multicolumn{3}{|c|}{ Xiaoqing River sediment $(n=3)$} \\
\hline & \multirow{2}{*}{$\begin{array}{l}\text { Mean } \\
0.043\end{array}$} & \multirow{2}{*}{$\frac{\text { Max }}{0.121}$} & \multirow{2}{*}{$\frac{\operatorname{Min}}{-^{\mathrm{a}}}$} & \multirow{2}{*}{$\begin{array}{l}\text { Median } \\
0.029\end{array}$} & \multirow{2}{*}{$\begin{array}{l}\text { Mean } \\
0.089\end{array}$} & \multirow{2}{*}{$\begin{array}{l}\text { Max } \\
0.452\end{array}$} & \multirow{2}{*}{ Min } & \multirow{2}{*}{$\begin{array}{l}\text { Median } \\
0.038\end{array}$} & \multirow{2}{*}{$\begin{array}{l}\text { Estuary }(n=1) \\
0.035\end{array}$} & \multicolumn{2}{|c|}{ Riverine $(n=2)$} \\
\hline & & & & & & & & & & 0.155 & 0.315 \\
\hline PFPeA & - & - & - & - & - & 0.013 & - & - & 0.010 & 0.133 & 0.225 \\
\hline PFHxA & 0.006 & 0.043 & - & 0.004 & 0.004 & 0.031 & - & - & 0.040 & 0.208 & 0.392 \\
\hline PFHpA & - & 0.006 & - & - & - & 0.008 & - & - & 0.034 & 0.153 & 0.307 \\
\hline PFOA & 0.158 & 1.049 & 0.005 & 0.071 & 0.044 & 0.221 & 0.005 & 0.027 & 2.452 & 12.988 & 29.021 \\
\hline PFNA & 0.017 & 0.080 & 0.002 & 0.009 & 0.016 & 0.087 & 0.002 & 0.009 & 0.005 & 0.052 & 0.178 \\
\hline PFDA & 0.011 & 0.025 & - & 0.012 & 0.020 & 0.067 & - & 0.015 & 0.017 & 0.089 & 0.245 \\
\hline PFUdA & 0.010 & 0.034 & - & - & 0.020 & 0.084 & - & - & - & 0.120 & 0.319 \\
\hline PFDoA & 0.004 & 0.013 & - & - & 0.005 & 0.027 & - & - & 0.004 & 0.106 & 0.352 \\
\hline PFTrDA & - & - & - & - & - & 0.009 & - & - & - & 0.040 & 0.127 \\
\hline PFTeDA & - & - & - & - & - & 0.009 & - & - & - & 0.017 & 0.059 \\
\hline PFBS & 0.158 & 0.348 & 0.036 & 0.111 & 0.204 & 1.695 & 0.012 & 0.098 & 0.070 & 0.141 & 0.106 \\
\hline PFHxS & 0.009 & 0.028 & - & - & 0.010 & 0.074 & - & - & - & 0.046 & 0.098 \\
\hline PFOS & 0.107 & 0.188 & 0.061 & 0.098 & 0.155 & 0.435 & 0.027 & 0.109 & 0.082 & 0.101 & 0.176 \\
\hline$\Sigma$ PFCAs & 0.259 & 1.143 & 0.044 & 0.133 & 0.208 & 0.775 & 0.053 & 0.115 & 2.604 & 14.061 & 31.540 \\
\hline$\Sigma$ PFSAs & 0.276 & 0.462 & 0.102 & 0.258 & 0.370 & 1.796 & 0.114 & 0.259 & 0.152 & 0.288 & 0.380 \\
\hline$\Sigma$ PFAS & 0.535 & 1.583 & 0.218 & 0.442 & 0.578 & 1.953 & 0.167 & 0.358 & 2.756 & 14.350 & 31.920 \\
\hline
\end{tabular}

a “_" means data below limitation of detection. 


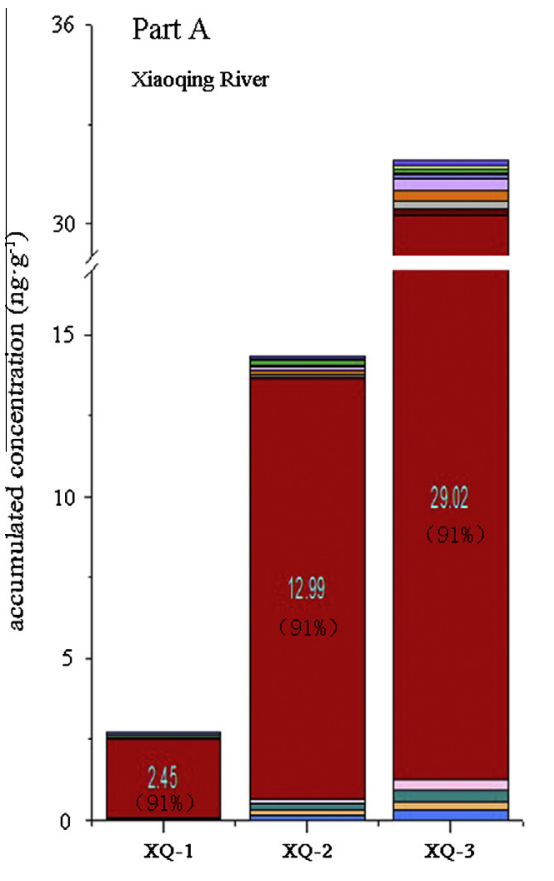

Part B

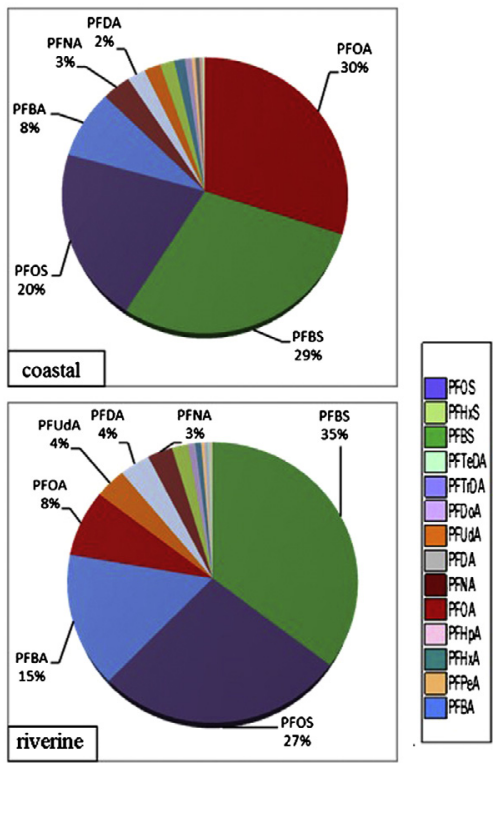

Fig. 2. Composition of PFAS in Xiaoqing River (Part A) and percentage composition of PFAS in coastal sediments and riverine sediments (Part B).

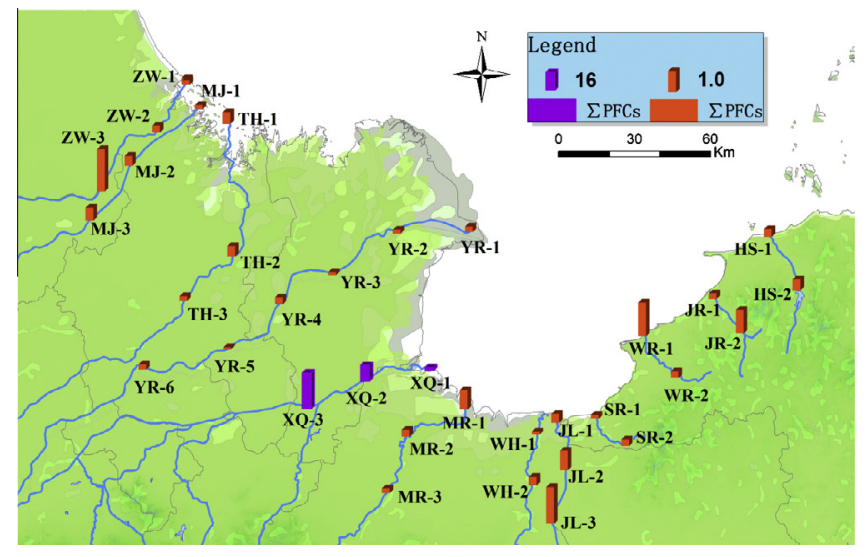

Fig. 3. Spatial distributions of $\Sigma$ PFAS in sediments from South Bohai coastal rivers.

several anomalous points opposite to this trend. However, the distribution of PFAS in the coastal environment is influenced by many factors, such as partitioning behaviors between sediment and water (Higgins and Luthy, 2006), the deposition of volatile compounds in the air (Dreyer et al., 2009), and the transport of PFAS in water (Ahrens et al., 2009). Thus, more information is needed to identify sources of PFAS in sediment of South Bohai coastal rivers.

\subsection{Comparison of PFAS in sediments with other Asian countries}

PFOA and PFOS were the most frequently detected PFAS compounds in the environment. Their concentrations in other coastal and riverine sediments in China and other Asian countries were compared in this study (Table 3). Compared with other riverine and coastal sediments in China, concentrations of PFOS in sediments from South Bohai coastal rivers, excluding the Xiaoqing River, $\left(0.03-0.36 \mathrm{ng} \mathrm{g}^{-1} \mathrm{dw}\right)$ were comparable to those found in the Daliao River system of northeast China $\left(0.06-0.37 \mathrm{ng} \mathrm{g}^{-1} \mathrm{dw}\right)$
(Bao et al., 2009) and Yangtzi River Estuary, Shanghai (n.d.$0.46 \mathrm{ng} \mathrm{g}^{-1} \mathrm{dw}$ ) (Bao et al., 2010b), but lower than those observed in North Bohai coastal rivers (n.d.-1.97 $\mathrm{ng} \mathrm{g}^{-1} \mathrm{dw}$ ) (Wang et al., 2011b), Laizhou Bay rivers (<0.03-1.6 $\mathrm{ng} \mathrm{g}^{-1} \mathrm{dw}$ ) (Zhao et al., 2013), Haihe River, Tianjin (1.76-7.32 $\mathrm{ng} \mathrm{g}^{-1} \mathrm{dw}$ ) (Li et al., 2011) and Zhujiang River, Guangzhou (n.d.-3.1 $\mathrm{ng} \mathrm{g}^{-1} \mathrm{dw}$ ) (Bao et al., 2010b). Concentrations of PFOS in Xiaoqing River sediments measured in this study $\left(0.08-0.18 \mathrm{ng} \mathrm{g}^{-1} \mathrm{dw}\right)$ were lower than those observed in other studies of rivers in China. When compared with similar studies in other riverine and coastal sediments of other Asian countries, PFOS in the Xiaoqing River sediments of China had comparable concentrations with those in the Ariake Sea in Japan (0.09-0.14 $\mathrm{ng} \mathrm{g}^{-1} \mathrm{dw}$ ) (Nakata et al., 2006). Concentrations of PFOS in South Bohai coastal river sediments including the Xiaoqing River were lower than those reported in estuarine and coastal areas of Korea (n.d.-2.0 $\mathrm{ng} \mathrm{g}^{-1} \mathrm{dw}$ ) (Naile et al., 2010), Western coast of Korea $\left(<0.2-5.8 \mathrm{ng} \mathrm{g}^{-1} \mathrm{dw}\right)$ (Naile et al., 2013), Tokyo Bay, Japan (mean: $1.66 \mathrm{ng} \mathrm{g}^{-1} \mathrm{dw}$ ) (Zushi et al., 2010) and Kyoto area River, Japan ( $<0.33-11 \mathrm{ng} \mathrm{g}^{-1} \mathrm{dw}$ ) (Senthilkumar et al., 2007).

Concentrations of PFOA were highest in sediments of the Xiaoqing River, (Table 3), with a maximum of $29.02 \mathrm{ng} \mathrm{g}^{-1} \mathrm{dw}$, and were higher than those in other riverine and coastal sediment studies in China including North Bohai Sea coastal rivers (n.d.-0.542 ng g $^{-1}$ dw) (Wang et al., 2011b), Daliao River system of northeast China (0.09-0.17 $\mathrm{ng} \mathrm{g}^{-1} \mathrm{dw}$ ) (Bao et al., 2009), Haihe River, Tianjin (0.92-3.69 $\mathrm{ng} \mathrm{g}^{-1} \mathrm{dw}$ ) (Li et al., 2011), Yangtzi River Estuary, Shanghai (0.20-0.64 $\mathrm{ng} \mathrm{g}^{-1} \mathrm{dw}$ ) (Bao et al., 2010b) and Zhujiang River, Guangzhou (0.09-0.28 ng g $^{-1} \mathrm{dw}$ ) (Bao et al., 2010b), but were lower than the maximum concentration of $76.9 \mathrm{ng} \mathrm{g}^{-1} \mathrm{dw}$, which was measured in sediment of Laizhou Bay (Zhao et al., 2013). PFOA in the Xiaoqing River of China had the highest concentration compared with other Asian countries, such as estuarine and coastal areas of Korea (n.d.-2.0 $\mathrm{ng} \mathrm{g}^{-1} \mathrm{dw}$ ) (Naile et al., 2010), Western coast of Korea $\left(<0.2-2.4 \mathrm{ng} \mathrm{g}^{-1} \mathrm{dw}\right.$ ) (Naile et al., 2013), Tokyo Bay, Japan (0.12-0.45 $\mathrm{ng} \mathrm{g}^{-1} \mathrm{dw}$ ) (Zushi et al., 2010), Ariake Sea, Japan (0.84-1.10 $\mathrm{ng} \mathrm{g}^{-1} \mathrm{dw}$ ) (Nakata et al., 2006), Kyoto area River, Japan (1.3-3.9 ng g $^{-1} \mathrm{dw}$ ) (Senthilkumar et al., 2007), and Ganges River of India $\left(<0.5-14.09 \mathrm{ng} \mathrm{g}^{-1} \mathrm{dw}\right.$ ) (Corsolini et al., 
Table 3

Comparison of PFAS in surface sediment in China and other Asian countries.

\begin{tabular}{|c|c|c|c|c|c|}
\hline Sampling & Year & $n$ & Concentration & ng g ${ }^{-1} \mathrm{dw}$ & References \\
\hline China & & PFOS & PFOA & & \\
\hline South Bohai Sea coast rivers ${ }^{a}$ & 2011 & 33 & $0.03-0.36$ & $<0.01-1.05$ & This study \\
\hline Xiaoqing River in South Bohai Bay & 2011 & 3 & $0.08-0.18$ & $2.45-29.02$ & This study \\
\hline North Bohai Sea coastal rivers & 2008 & 35 & n.d. ${ }^{b}-1.97$ & n.d. -0.542 & Wang et al. (2011) \\
\hline Daliao River system of northeast China & 2008 & 10 & $0.06-0.37$ & $0.09-0.17$ & Bao et al. (2009) \\
\hline Haihe River, Tianjin & 2010 & 16 & $1.76-7.32$ & $0.92-3.69$ & Li et al. (2011) \\
\hline Laizhou Bay rivers & 2009 & 24 & $<0.03^{\mathrm{c}}-1.6$ & $<0.04-76.9$ & Zhao et al. (2013) \\
\hline Yangtzi River Estuary, Shanghai & 2009 & 9 & n.d. -0.46 & $0.20-0.64$ & Bao et al. (2010) \\
\hline Zhujiang River, Guangzhou & 2009 & 13 & n.d.-3.1 & $0.09-0.28$ & Bao et al. (2010) \\
\hline \multicolumn{6}{|l|}{ Other Asian countries } \\
\hline Estuarine and coastal areas of Korea & 2008 & 12 & n.d. -2.0 & n.d. -2.0 & Naile et al. (2010) \\
\hline Western coast of Korea & 2009 & 5 & $<0.2-5.8$ & $<0.2-2.4$ & Naile et al. (2013) \\
\hline Tokyo Bay, Japan & 2004 & 1 & 1.66 & $0.12-0.45$ & Zushi et al. (2010) \\
\hline Ariake Sea (Japan) & 2004 & 5 & $0.09-0.14$ & $0.84-1.10$ & Nakata et al. (2006) \\
\hline Kyoto area River (Japan) & 2003 & 4 & $<0.33-11$ & $1.3-3.9$ & Senthilkumar et al. (2007) \\
\hline Ganges River (India) & 2011 & 13 & $<0.5$ & $<0.5-14.09$ & Corsolini et al. (2012) \\
\hline
\end{tabular}

a South Bohai coastal rivers in this study exclude the Xiaoqing River.

b n.d. = not detected.

c $<x$ means below the respective quantification limit (LOQ).

2012). PFOA in sediment of the remaining 11 coastal rivers in this study $\left(<0.01-1.05 \mathrm{ng} \mathrm{g}^{-1} \mathrm{dw}\right)$ were higher than those in North Bohai Sea coastal rivers, Daliao River system, Yangtze River Estuary, Zhujiang River as well as Tokyo Bay, Japan, but were lower than those in the Haihe River and adjacent country riverine or coastal areas like those in Korea, the Kyoto area River in Japan and Ganges River in India.

In general, due to the stronger affinity of PFOS to sediments than PFOA (Ahrens, 2011; Higgins and Luthy, 2006), concentrations of PFOS were higher than those of PFOA in sediments of North Bohai Sea coastal rivers, the Daliao River system, Haihe River, Tianjin, Zhujiang River, Guangzhou, western coast of Korea and Tokyo Bay, Japan. However, situations might be quite different because of various influences of industrial and human activities. Sediments of the Xiaoqing River contained an extremely high concentration of PFOA compared with other riverine and coastal sediment studies in both China and other Asian countries, which indicated the potential existence of fluoropolymer industries along this river. Further study is needed to identify the exact source of PFOA in the Xiaoqing River.

\subsection{Partitioning of PFAS between water and sediment}

The partitioning behavior of PFAS between sediment and surface water is crucial for understanding the transport mechanism of PFAS in the environment (Yang et al., 2011; Zhao et al., 2012). The distribution coefficient $\left(K_{d}\right)$ is the most commonly used parameter in the evaluation of organic pollutants partitioning in the water environment. $K_{d}$ was calculated (Eq. (1)).

$K_{d}=C_{s} / C_{w}$

where $C_{s}$ and $C_{w}$ are concentrations of PFAS in sediment and surface water in the unit of $\mathrm{ng} \mathrm{kg}^{-1} \mathrm{dw}$ and $\mathrm{ng} \mathrm{L}^{-1}$, respectively. Concentrations of PFAS in surface water used to calculate the $K_{d}$ were from an unpublished paper of our research group (look for the data in Table S4). Previous studies showed that the fraction of organic carbon $\left(f_{o c}\right)$ has a significant influence on the sorption and transport of PFAS on sediment (Higgins and Luthy, 2006). Hence, the organic carbon normalized partition coefficient $\left(K_{o c}\right)$ provides a better indication of the partitioning behavior. $K_{o c}$ was calculated (Eq. (2)).

$K_{o c}=K_{d} \times 100 / f_{o c}$

where $f_{o c}$ is the organic carbon fraction in sediment (\%), which was determined using a Potassium Dichromate Oxidation-Spectrophotometric method (Chatterjee et al., 2009; Da Silva Dias et al., 2012).
Average values of $\log K_{d}$ and $\log K_{o c}$ for PFAS are shown in Table 4 (see Table S3 for detailed information). PFOA in the study area had an average $\log K_{o c}$ of 2.68, which is similar to the result (2.63) of a study in Netherlands (Kwadijk et al., 2010). The $\log K_{o c}$ of PFOA was higher than previously reported values, 2.06 (Higgins and Luthy, 2006), 2.09 and 2.17 (Zhao et al., 2012) and 2.28 (Yang et al., 2011), but was lower than the reported value of 3.7 in Tianjin, China (Li et al., 2011). The $\log K_{o c}$ of PFOS was 3.75, which was also higher than the results of other studies, 2.57 (Higgins and Luthy, 2006), 2.88 (Yang et al., 2011), 3.04 (You et al., 2010), 2.68 and 2.97 (Zhao et al., 2012), 3.16 (Kwadijk et al., 2010), and the range observed by 3M Co. (2.57-3.1) (3M Company, 2000). When partition of PFAS between water and sediment from Tokyo Bay, Japan was calculated, a slightly higher $\log K_{o c}$ was observed for PFOS of $3.8 \pm 0.1 \mathrm{~L} \mathrm{~kg}^{-1}$. These results suggest that properties of sediments and water conditions can affect partitioning of PFAS in the environment (Hong et al., 2013).

In this study, the average $\log K_{o c}$ for PFCAs ranged from 2.33 for PFHpA to 4.19 for PFUdA. The average $\log K_{o c}$ was directly proportional to number of carbons in PFCAs, which was consistent with previous reports (Higgins and Luthy, 2006; Ahrens et al., 2009). The exception occurred for PFBA and PFHpA, where a relatively high value $(3.02 \pm 0.45)$ and a low value $(2.33 \pm 0.49)$ were found for PFBA and PFHpA, respectively. There are many factors influencing the fate of PFAS in aquatic systems, but only limited data is

Table 4

Calculated average $\log K_{d}$ and $\log K_{o c}$ of individual PFAS.

\begin{tabular}{lrrclc}
\hline & $\mathrm{C}^{\mathrm{a}}$ & $\mathrm{N}^{\mathrm{b}}$ & $\begin{array}{l}\log K_{d}\left(\mathrm{~L} \mathrm{~kg}^{-1}\right) \\
(\text { mean } \pm \mathrm{SD})\end{array}$ & $\begin{array}{l}\log K_{o c}\left(\mathrm{~L} \mathrm{~kg}^{-1}\right) \\
(\text { mean } \pm \mathrm{SD})\end{array}$ & $\begin{array}{l}\text { Correlation between } \\
\log K_{d} \text { and } f_{o c}\left(i^{2}\right)^{\mathrm{c}}\end{array}$ \\
\hline PFBA & 4 & 33 & $1.00 \pm 0.38$ & $3.02 \pm 0.45$ & $0.14(p>0.05)$ \\
PFPeA & 5 & 19 & $0.46 \pm 0.24$ & $2.40 \pm 0.52$ & $-0.02(p>0.05)$ \\
PFHxA & 6 & 18 & $0.59 \pm 0.33$ & $2.55 \pm 0.51$ & $-0.02(p>0.05)$ \\
PFHpA & 7 & 14 & $0.45 \pm 0.35$ & $2.33 \pm 0.49$ & $0.13(p>0.05)$ \\
PFOA & 8 & 35 & $0.63 \pm 0.51$ & $2.68 \pm 0.51$ & $0.18(p>0.05)$ \\
PFNA & 9 & 33 & $1.03 \pm 0.49$ & $3.07 \pm 0.43$ & $0.44(p<0.05)$ \\
PFDA & 10 & 24 & $1.60 \pm 0.51$ & $3.59 \pm 0.55$ & $0.42(p<0.05)$ \\
PFUdA & 11 & 7 & $2.25 \pm 0.66$ & $4.19 \pm 0.52$ & $0.24(p>0.05)$ \\
PFBS & 4 & 24 & $2.18 \pm 0.66$ & $4.24 \pm 0.59$ & $0.12(p>0.05)$ \\
PFHxS & 6 & 9 & $2.24 \pm 0.55$ & $4.15 \pm 0.47$ & $0.34(p<0.05)$ \\
PFOS & 8 & 35 & $1.7 \pm 0.39$ & $3.75 \pm 0.44$ & $0.05(p>0.05)$ \\
\hline
\end{tabular}

a Number of carbon atoms in PFAS carbon chain.

b The available number of sampling sites in which particular PFAS were detected from both sediment and surface water.

c Spearman's correlation, $p$ value $<0.05$; analyzed by the statistical software package SPSS V21. 
Table 5

$f_{o c}$-normalized concentrations and hazard quotient (HQ) of PFAS.

\begin{tabular}{|c|c|c|c|c|c|c|}
\hline \multirow[t]{2}{*}{ Site number } & \multirow[t]{2}{*}{ River } & \multirow[t]{2}{*}{$n$} & \multicolumn{2}{|c|}{$\begin{array}{l}f_{o c} \text {-normalized concentrations }\left(\mathrm{ng} \mathrm{g}^{-1} f_{o c}{ }^{-1}\right) \\
(\text { mean }(\text { minimum-maximum }))\end{array}$} & \multicolumn{2}{|l|}{$\begin{array}{l}\text { Hazard quotient (HQ) } \\
\text { (minimum; maximum) }\end{array}$} \\
\hline & & & PFOA & PFOS & PFOA & PFOS \\
\hline HS-1,2 & Huangshui River & 2 & 0.03(n.a. $\left.{ }^{\mathrm{a}}-0.06\right)$ & $0.05(0.04-0.06)$ & n.a.; $1.05 \mathrm{E}-04$ & $1.16 \mathrm{E}-03 ; 1.68 \mathrm{E}-03$ \\
\hline $\mathrm{JL}-1,2,3$ & Jiaolai River & 3 & $0.11(0.02-0.23)$ & $0.26(0.09-0.38)$ & $3.45 \mathrm{E}-05 ; 1.3 \mathrm{E}-04$ & $2.39 \mathrm{E}-03 ; 0.01$ \\
\hline JR-1,2 & Jie River & 2 & 0.01(n.a.-0.02) & $0.25(0.14-0.35)$ & n.a.; 3.8E-05 & $3.83 \mathrm{E}-03 ; 9.44 \mathrm{E}-03$ \\
\hline $\mathrm{MJ}-1,2,3$ & Majia River & 3 & $0.10(0.05-0.17)$ & $0.16(0.08-0.20)$ & $7.9 \mathrm{E}-05 ; 2.93 \mathrm{E}-04$ & $2.24 \mathrm{E}-03 ; 5.46 \mathrm{E}-03$ \\
\hline MR-1,2,3 & Mi River & 3 & $0.55(0.02-1.57)$ & $0.33(0.15-0.62)$ & $4.15 \mathrm{E}-05 ; 2.73 \mathrm{E}-03$ & $4.14 \mathrm{E}-03 ; 0.02$ \\
\hline SR-1,2 & Sha River & 2 & $0.03(0.02-0.05)$ & $0.22(0.17-0.26)$ & $3.15 \mathrm{E}-05 ; 9.26 \mathrm{E}-05$ & $4.56 \mathrm{E}-03 ; 7.08 \mathrm{E}-03$ \\
\hline $\mathrm{TH}-1,2,3$ & Tuhai River & 3 & $0.02(0.01-0.03)$ & $0.04(0.03-0.06)$ & $2.5 \mathrm{E}-05 ; 4.42 \mathrm{E}-05$ & $7.83 \mathrm{E}-04 ; 1.59 \mathrm{E}-03$ \\
\hline WH-1,2,3 & Wei River & 3 & $0.04(0.01-0.10)$ & $0.11(0.03-0.24)$ & $7.74 \mathrm{E}-06 ; 1.74 \mathrm{E}-04$ & $9.22 \mathrm{E}-04 ; 6.41 \mathrm{E}-03$ \\
\hline WR-1,2 & Wang River & 2 & $2.29(0.01-4.57)$ & $0.25(0.09-0.40)$ & $1.69 \mathrm{E}-05 ; 7.96 \mathrm{E}-03$ & $2.456 \mathrm{E}-03 ; 0.01$ \\
\hline$X Q-1,2,3$ & Xiaoqing River & 3 & $33.28(3.52-71.30)$ & $0.25(0.12-0.43)$ & $6.14 \mathrm{E}-03 ; 0.12$ & $3.16 \mathrm{E}-03 ; 0.01$ \\
\hline YR-1,2,3,4,5,6 & Yellow River & 6 & 0.02(n.a.-0.06) & $0.12(0.01-0.20)$ & n.a.; $1.05 \mathrm{E}-4$ & $2.69 \mathrm{E}-03 ; 5.39 \mathrm{E}-03$ \\
\hline ZW-1,2,3,4 & Zhangwei River & 4 & $0.05(0.02-0.10)$ & $0.07(0.04-0.09)$ & $3.55 \mathrm{E}-05 ; 1.81 \mathrm{E}-4$ & $1.00 \mathrm{E}-03 ; 2.53 \mathrm{E}-03$ \\
\hline $\mathrm{NPEC}_{\mathrm{PFOS}}{ }^{\mathrm{b}}$ & $37.154 \mu \mathrm{g} \mathrm{kg}^{-1}$ & & & & & \\
\hline
\end{tabular}

${ }^{\text {a }}$ n.a. = not available, used as zero in calculating the mean value.

b PNEC in sediment derived by equilibrium partitioning method from PNEC in water.

available on their distribution between water and sediment (Kwadijk et al., 2010; Li et al., 2011; Hong et al., 2013). Longer carbon chain increases hydrophobicity of PFAS and enhances interactions of PFAS with carbonaceous materials, so it is easy to understand that $\log K_{o c}$ s of PFCAs increase as the carbon chain elongates.

Partitioning of PFAS between sediment and water was also influenced by solution parameters such as $\mathrm{pH}$ and sediment organic carbon fraction $\left(f_{o c}\right)$ (Higgins and Luthy, 2006; Liu and Lee, 2005; Ahrens et al., 2010b). Correlations between $K_{d} \mathrm{~s}$ and $f_{o c}$ were made for individual PFAS (Table 4). Significant correlations were found between $f_{o c}$ and $K_{d}$ S of PFNA, PFDA and PFHxS $(p<0.05)$. The result was in accordance with the previous laboratory research of Higgins and Luthy (2006). As shown by some field research that there were no significant correlations between $f_{o c}$ and $K_{d}$ s of PFAS $(p>0.05)$ (Kwadijk et al., 2010), we also found the same result in PFAS homologs except for PFNA, PFDA and PFHxS.

Partitioning of PFAS between sediment and water varies in each aqueous system, other characteristics of sediment might also influence the partitioning of PFAS. The understanding of PFAS fate in aqueous environment is still incomplete and relevant laboratory studies were different from some field-based distribution coefficients studies between sediment and water (Higgins and Luthy, 2006; Ahrens et al., 2010b; Kwadijk et al., 2010). Studies under laboratory conditions showed that adsorption of PFAS were generally greater with decreasing $\mathrm{pH}$ of water and increasing organic carbon fractions of sediments (Higgins and Luthy, 2006). But field studies could not always find such correlations because of complicated natural and social effects. For example, partitioning study of PFAS in the Youngsan and Nakdong River Estuarine systems in South Korea suggested the $\mathrm{pH}$ and $\mathrm{f}_{\mathrm{oc}}$ were not significantly correlated with values of $K_{d}$ s for PFAS (Hong et al., 2013). This was mainly due to the different features of aqueous systems in the specific study area. It is almost impossible to determine all physicochemical parameters of a river system, so the partitioning behavior may be obscured by other properties of the system that we did not pay attention to in field studies. Thus, more field studies on partitioning are still necessary to help improve our understanding on the partitioning processes and the fate of PFAS in aqueous environments.

\subsection{Preliminary environmental hazard assessment}

Since sediment is considered to be the final sink and reservoir of many contaminants, information about contamination of sediments with PFAS is essential in the hazard assessment of aqua- tic systems. PFOS and PFOA can cause both acute and chronic toxicity in freshwater fish and invertebrates (Hekster, 2002; Hekster et al., 2003; Beach et al., 2005; Giesy et al., 2009). PFOS in water of the Nanmen River, China, concentrations of which were as high as $6.05 \mu \mathrm{g} \mathrm{L}^{-1}$, was determined to pose significant hazard to aquatic organisms (Lin et al., 2010). Concentrations of PFOS and PFOA in sediments from Laizhou Bay were deemed to be of low hazard to benthic invertebrates (Zhao et al., 2013).

In this study, the assessment of hazard was performed based on the hazard quotient (HQ) method where a HQ $>1$ indicates potential for hazard. In this method measured concentrations in the environment are compared to predicted no-effect concentrations (PNEC) for individual PFAS. PNEC concentrations are derived from toxicity data and uncertainty factors and are meant to be protective. The PNEC to which measured concentrations are compared can be in various matrices, including water, sediment or tissues of organisms (Giesy et al., 2009; Peng et al., 2010; Yoo et al., 2008; Zheng et al., 2012). Because toxicity tests of PFAS to sediment organisms are insufficient until now, the equilibrium partitioning method (EqP) was applied to calculate the $\mathrm{PNEC}_{\text {sediment }}$ from $\mathrm{PNEC}_{\text {water }}$ (van Vlaardingen and Verbruggen, 2007). The PNEC $\mathrm{C}_{\text {water }}$ was calculated to be $25 \mu \mathrm{g} \mathrm{L}^{-1}$ for PFOS, based on the lowest no-observed effect concentration (NOEC) for fathead minnows (Beach et al., 2005; Brooke et al., 2004), and $1.25 \mathrm{mg} \mathrm{L}^{-1}$ for PFOA, based on the NOEC of algae (Colombo et al., 2008; Giesy et al., 2009). The $f_{o c}$-normalized partitioning coefficient $\left(\log K_{o c}\left(\mathrm{~L} \mathrm{~kg}^{-1}\right)\right)$, was 2.57 for PFOS and 2.06 for PFOA (Higgins and Luthy, 2006). Both the derived PNECs and the measured environment concentrations were $f_{o c}$-normalized. HQs of both PFOS and PFOA were all lower than 1.0 for the 12 rivers studied (Table 5 ), which indicates that no significant hazards would be expected to be caused by concentrations of individual PFAS in sediments of South Bohai coastal rivers. The highest PFOS and PFOA concentrations ( $0.62 \mathrm{ng} \mathrm{g}^{-1} f_{o c}{ }^{-1} \mathrm{dw}$ for PFOS and $71.30 \mathrm{ng} \mathrm{g}^{-1} f_{o c}{ }^{-1} \mathrm{dw}$ for PFOA) occurred to coastal sediments at sites MR- 1 and XQ-3, and had the highest HQs of 0.02 and 0.12 , respectively. These results indicate PFOS had relative higher hazard to ecosystem of the Mi River while PFOA had relative higher hazard to ecosystem of the Xiaoqing River.

\section{Conclusions}

Detectable concentrations of PFAS, especially PFOA with the highest concentration of $29.02 \mathrm{ng} \mathrm{g}^{-1} \mathrm{dw}$, were found in sediments of the Xiaoqing River, but in the other 11 rivers studied, concentrations of $\Sigma$ PFAS ranged from $0.218 \mathrm{ng} \mathrm{g}^{-1} \mathrm{dw}$ 
to $1.583 \mathrm{ng} \mathrm{g}^{-1} \mathrm{dw}$ (mean: $0.535 \mathrm{ng} \mathrm{g}^{-1} \mathrm{dw}$ ) in coastal sediments and form $0.167 \mathrm{ng} \mathrm{g}^{-1} \mathrm{dw}$ to $1.953 \mathrm{ng} \mathrm{g}^{-1} \mathrm{dw}$ (mean: $0.578 \mathrm{ng} \mathrm{g}^{-1} \mathrm{dw}$ ) in riverine sediments. The dominant compounds in the coastal and riverine sediments are PFOA and PFBS with contributions of $30 \%$ and $35 \%$, respectively. The high concentrations of PFAS in this study area were mainly attributed to intensive industries including fluoropolymer manufacturing as well as a dense population. Partitioning of PFNA, PFDA and PFHxS between sediment and water were significantly correlated with the organic carbon fraction, as determined by partitioning analysis. Preliminary environmental hazard assessment showed that PFOS posed the highest hazard and was highest in the Mi River, but none of the HQs exceeded the threshold value of 1.0 that would be indicative of potential adverse effects. The highest potential hazard of PFOA was in the Xiaoqing River, but again the HQ was lower than the threshold for adverse effects.

\section{Acknowledgements}

This study was supported by the National Natural Science Foundation of China under Grant Nos. 41171394 and 41371488, National Fundamental Field Study Program with Grant No. 2013FY111100, and Key Research Program of the Chinese Academy of Sciences under Grant No. KZZD-EW-TZ-12. We would like to thank the editors and reviewers for their valuable comments and suggestions. Prof. Giesy was supported by the Einstein Professorship Program of the Chinese Academy of Sciences and the Canada Research Chair Program.

\section{Appendix A. Supplementary material}

Supplementary data associated with this article can be found, in the online version, at http://dx.doi.org/10.1016/j.marpolbul.2013. 12.042 .

\section{References}

3M, 1999. Fluorochemical Use, Distribution and Release Overview. U.S. Environmental Protection Agency, Docket AR 226-0550.

$3 \mathrm{M}, 2000$. Soil adsorption/desorption study of potassium perfluorooctane sulfonate (PFOS). US Environmental Protection Agency, St. Paul, MN, Docket AR 2261030a 1030.

Ahrens, L., 2011. Polyfluoroalkyl compounds in the aquatic environment: a review of their occurrence and fate. J. Environ. Monit. 13, 20-31.

Ahrens, L., Gerwinski, W., Theobald, N., Ebinghaus, R., 2010a. Sources of polyfluoroalkyl compounds in the North Sea, Baltic Sea and Norwegian Sea: evidence from their spatial distribution in surface water. Mar. Pollut. Bull. 60, $255-260$.

Ahrens, L., Taniyasu, S., Yeung, L.W.Y., Yamashita, N., Lam, P.K.S., Ebinghaus, R., 2010b. Distribution of polyfluoroalkyl compounds in water, suspended particulate matter and sediment from Tokyo Bay, Japan. Chemosphere 79, 266-272.

Ahrens, L., Yamashita, N., Yeung, L.W.Y., Taniyasu, S., Horii, Y., Lam, P.K.S., Ebinghaus, R., 2009. Partitioning behavior of per- and polyfluoroalkyl compounds between pore water and sediment in two sediment cores from Tokyo Bay, Japan. Environ. Sci. Technol. 43, 6969-6975.

Bao, J., Jin, Y.H., Liu, W., Ran, X.R., Zhang, Z.X., 2009. Perfluorinated compounds in sediments from the Daliao River system of northeast China. Chemosphere 77, 652-657.

Bao, J., Liu, W., Liu, L., Jin, Y.H., Dai, J.Y., Ran, X.R., Zhang, Z.X., Tsuda, S., 2010a. Perfluorinated compounds in the environment and the blood of residents living near fluorochemical plants in Fuxin, China. Environ. Sci. Technol. 45, 80758080.

Bao, J., Liu, W., Liu, L., Jin, Y.H., Ran, X.R., Zhang, Z.X., 2010b. Perfluorinated compounds in urban river sediments from Guangzhou and Shanghai of China. Chemosphere 80, 123-130.

Beach, S.A., Newsted, J.L., Coady, K., Giesy, J.P., 2005. Ecotoxicological evaluation of perfluorooctanesulfonate (PFOS). Rev. Environ. Contamn. Toxicol. 186, 133-174.

Brooke, D., Footitt, A., Nwaogu, T.A., 2004. Environmental Risk Evaluation Report: Perfluorooctane Sulfonate (PFOS). Environment Agency. <http://www. environment-agency.gov.uk/commondata/105385/pfos_rer_sept04_864557. pdf>.
Chatterjee, A., Lal, R., Wielopolski, L., Martin, M.Z., Ebinger, M.H., 2009. Evaluation of different soil carbon determination methods. Crit. Rev. Plant Sci. 28, 164-178.

Colombo, I., de Wolf, W., Thompson, R.S., Farrar, D.G., Hoke, R.A., L’Haridon, J., 2008 Acute and chronic aquatic toxicity of ammonium perfluorooctanoate (APFO) to freshwater organisms. Ecotoxicol. Environ. Saf. 71, 749-756.

Corsolini, S., Sarkar, S.K., Guerranti, C., Bhattacharya, B.D., Rakshit, D., Jonathan, M.P., Godhantaraman, N., 2012. Perfluorinated compounds in surficial sediments of the Ganges River and adjacent Sundarban mangrove wetland, India. Mar. Pollut. Bull. 64, 2829-2833.

Da Silva Dias, R., De Abreu, C.A., De Abreu, M.F., Paz-Ferreiro, J., Matsura, E.E., Paz González, A., 2012. Comparison of methods to quantify organic carbon in soil samples from São Paulo State, Brazil. Commun. Soil Sci. Plant Anal. 44, 429-439.

Dreyer, A., Weinberg, I., Temme, C., Ebinghaus, R., 2009. Polyfluorinated compounds in the atmosphere of the Atlantic and Southern oceans: evidence for a global distribution. Environ. Sci. Technol. 43, 6507-6514.

Fair, P.A., Houde, M., Hulsey, T.C., Bossart, G.D., Adams, J., Balthis, L., Muir, D.C.G. 2012. Assessment of perfluorinated compounds (PFCs) in plasma of bottlenose dolphins from two southeast US estuarine areas: relationship with age, sex and geographic locations. Mar. Pollut. Bull. 64, 66-74.

Giesy, J.P., Kannan, K., 2001. Global distribution of perfluorooctane sulfonate in wildlife. Environ. Sci. Technol. 35, 1339-1342.

Giesy, J.P., Kannan, K., 2002. Perfluorochemical surfactants in the environment. Environ. Sci. Technol. 36, 146A-152A.

Giesy, J.P., Naile, J., Yi, W., Khim, J.S., Jones, P.D., Newsted, J.L., 2009. Aquatic toxicology of perfluorinated chemicals. Crit. Rev. Environ. Toxicol. 202, 1-52.

Hekster, F., Laane, R.P.M. Voogt, P., 2003. Environmental and toxicity effects of perfluoroalkylated substances. Rev. Environ. Contam. Toxicol. 179, 99-121.

Hekster, F.M., 2002. Perfluoroalkylated Substances: Aquatic Environmental Assessment. Rijksinstituut voor Kust en Zee/RIKZ, Den Haag.

Higgins, C.P., Field, J.A., Criddle, C.S., Luthy, R.G., 2005. Quantitative determination of perfluorochemicals in sediments and domestic sludge. Environ. Sci. Technol. 39, 3946-3956.

Higgins, C.P., Luthy, R.G., 2006. Sorption of perfluorinated surfactants on sediments. Environ. Sci. Technol. 40, 7251-7256.

Hoff, P.T., Van Campenhout, K., Van de Vijver, K., Covaci, A., Bervoets, L., Moens, L. Huyskens, G., Goemans, G., Belpaire, C., Blust, R., De Coen, W., 2005. Perfluorooctane sulfonic acid and organohalogen pollutants in liver of three freshwater fish species in Flanders (Belgium): relationships with biochemical and organismal effects. Environ. Pollut. 137, 324-333.

Hong, S.J., Khim, J.S., Park, J.S., Kim, M., Kim, W.K., Jung, J., Hyun, S., Kim, J.G., Lee, H. Choi, H.J., Codling, G., Giesy, J.P., 2013. In situ fate and partitioning of waterborne perfluoroalkyl acids (PFFAs) in the Youngsan and Nakdong River estuaries of South Korea. Sci. Total. Environ., 136-145.

Hu, W.Y., Wang, T.Y., Khim, J.S., Luo, W., Jiao, W.T., Lu, Y.L., Naile, J.E., Chen, C.L. Zhang, X., Giesy, J.P., 2010. HCH and DDT in sediments from marine and adjacent riverine areas of North Bohai Sea, China. Arch. Environ. Contam. Toxicol. 59, 71-79.

Ishibashi, H., Iwata, H., Kim, E.Y., Tao, L., Kannan, K., Tanabe, S., Batoev, V.B., Petrov, E.A., 2008. Contamination and effects of perfluorochemicals in baikal seal (Pusa sibirica). 2. Molecular characterization, expression level, and transcriptional activation of peroxisome proliferator-activated receptor $\alpha$. Environ. Sci. Technol. 42, 2302-2308.

Kannan, K., Koistinen, J., Beckmen, K., Evans, T., Gorzelany, J.F., Hansen, K.J., Jones P.D., Helle, E., Nyman, M., Giesy, J.P., 2001a. Accumulation of perfluorooctane sulfonate in marine mammals. Environ. Sci. Technol. 35, 1593-1598.

Kannan, K., Hansen, S.P., Franson, C.J., Bowerman, W.W., Hansen, K.J., Jones, P.D. Giesy, J.P., 2001b. Perfluorooctane sulfonate in fish-eating water birds including bald eagles and albatrosses. Environ. Sci. Technol. 35, 3065-3070.

Kannan, K., Newsted, J.L., Holbrook, R.S., Giesy, J.P., 2002a. Perfluorooctanesulfonate and related fluorinated hydrocarbons in mink and river otters from the United States. Environ. Sci. Technol. 36, 2566-2571.

Kannan, K., Corsolini, S., Falandysz, J., Oehme, G., Focardi, S., Giesy, J.P., 2002b. Perfluorooctane sulfonate and related fluorinated hydrocarbons in marine mammals, fish and birds from coasts of the Baltic and the Mediterranean Seas. Environ. Sci. Technol. 36, 3210-3216.

Kissa, E., 2001. Fluorinated surfactants and repellents. In: Surfactant Science Series, second ed., vol. 97, pp. 1-615.

Kwadijk, C.J.A.F., Korytár, P., Koelmans, A.A., 2010. Distribution of perfluorinated compounds in aquatic systems in The Netherlands. Environ. Sci. Technol. 44, 3746-3751.

Li, G.Y., 2004. The third test of water and sediment regulation conducted on the Yellow River. Yellow River 26 (10), 1-8.

Li, F.S., Sun, H.W., Hao, Z.N., He, N., Zhao, L.J., Zhang, T., Sun, T.H., 2011 Perfluorinated compounds in Haihe River and Dagu drainage canal in Tianjin, China. Chemosphere 84, 265-271.

Lin, A.Y.C., Panchangam, S.C., Ciou, P.S., 2010. High levels of perfluorochemicals in Taiwan's wastewater treatment plants and downstream rivers pose great risk to local aquatic ecosystems. Chemosphere 80, 1167-1174.

Liu, J.X., Lee, L.S., 2005. Solubility and sorption by soils of 8:2 fluorotelomer alcohol in water and cosolvent systems. Environ. Sci. Technol. 39, 7535-7540.

Luo, W., Lu, Y.L., Wang, T.Y., Hu, W.Y., Jiao, W.T., Naile, J.E., Khim, J.S., Giesy, J.P., 2010. Ecological risk assessment of arsenic and metals in sediments of coastal areas of northern Bohai and Yellow Seas, China. AMBIO 39, 367-375.

Mu, X.M., Zhang, X.Q., Shao, H.B., Gao, P., Wang, F., Jiao, J.Y., Zhu, J.L., 2012. Dynamic changes of sediment discharge and the influencing factors in the Yellow River, China, for the recent 90 years. CLEAN - Soil, Air, Water 40, 303-309. 
Naile, J.E., Khim, J.S., Hong, S.J., Park, J., Kwon, B.O., Ryu, J.S., Hwang, J.H., Jones, P.D., Giesy, J.P., 2013. Distributions and bioconcentration characteristics of perfluorinated compounds in environmental samples collected from the west coast of Korea. Chemosphere 90, 387-394.

Naile, J.E., Khim, J.S., Wang, T.Y., Chen, C.L., Luo, W., Kwon, B.O., Park, J., Koh, C.H. Jones, P.D., Lu, Y.L., Giesy, J.P., 2010. Perfluorinated compounds in water sediment, soil and biota from estuarine and coastal areas of Korea. Environ. Pollut. 158, 1237-1244.

Nakata, H., Kannan, K., Nasu, T., Cho, H.S., Sinclair, E., Takemura, A., 2006 Perfluorinated contaminants in sediments and aquatic organisms collected from shallow water and tidal flat areas of the Ariake Sea, Japan: environmental fate of perfluorooctane sulfonate in aquatic ecosystems. Environ. Sci. Technol. 40, 4916-4921.

Newsted, J.L., Jones, P.D., Coady, K., Giesy, J.P., 2005. Derivation of avian toxicity reference values (TRVs) and water values for perfluorooctane sulfonate (PFOS) Environ. Sci. Technol. 39, 9357-9362.

Newsted, N.L., Beach, S.A., Gallagher, S.P., Giesy, J.P., 2008. Acute and chronic effects of perfluorobutane sulfonate (PFBS) on the mallard and northern bobwhite quail. Arch. Environ. Contam. Toxicol. 54, 535-545.

van Vlaardingen, P.L.A., Verbruggen, E.M.J., 2007. Guidance for the Derivation of Environmental Risk Limits within the Framework of 'International and National Environmental Quality Standards Netherlands' (INS) Revision 2007.

Paul, A.G., Jones, K.C., Sweetman, A.J., 2008. A first global production, emission, and environmental inventory for perfluorooctane sulfonate. Environ. Sci. Technol. 43, 386-392.

Peng, H., Wei, O., Wan, Y., Giesy, J.P., Li, L., Hu, J., 2010. Tissue distribution and maternal transfer of poly- and perfluorinated compounds in Chinese sturgeon (Acipenser sinensis) implications for reproductive hazard. Environ. Sci. Technol. 44, 1868-1874.

Prevedouros, K., Cousins, I.T., Buck, R.C., Korzeniowski, S.H., 2006. Sources, fate and transport of perfluorocarboxylates. Environ. Sci. Technol. 40, 32-44.

Senthilkumar, K., Ohi, E., Sajwan, K., Takasuga, T., Kannan, K., 2007. Perfluorinated compounds in river water, river sediment, market fish, and wildlife samples from Japan. Bull. Environ. Contam. Toxicol. 79, 427-431.

Wang, P., Wang, T.Y., Giesy, J.P., Lu, Y.L., 2013. Perfluorinated compounds in soils from Liaodong Bay with concentrated fluorine industry parks in China. Chemosphere 91, 751-757.

Wang, T.Y., Chen, C.L., Naile, J.E., Khim, J.S., Giesy, J.P., Lu, Y.L., 2011a. Perfluorinated compounds in water, sediment and soil from Guanting Reservoir, China. Bull. Environ. Contam. Toxicol. 87, 74-79.

Wang, T.Y., Lu, Y.L., Chen, C.L., Naile, J.E., Khim, J.S., Park, J., Luo, W., Jiao, W.T., Hu, W.Y., Giesy, J.P., 2011b. Perfluorinated compounds in estuarine and coastal areas of north Bohai Sea, China. Mar. Pollut. Bull. 62, 1905-1914.
Wang, T.H., Wang, Y.W., Liao, C.Y., Cai, Y.Q., Jiang, G.B., 2009. Perspectives on the inclusion of perfluorooctane sulfonate into the Stockholm convention on persistent organic pollutants 1. Environ. Sci. Technol. 43, 5171-5175.

Wang, G.L., Ma, L.M., Sun, J.H., Zhang, G., 2010. Occurrence and distribution of organochlorine pesticides (DDT and $\mathrm{HCH}$ ) in sediments from the middle and lower reaches of the Yellow River, China. Environ. Monit. Assess. 168, 511521.

Xie, S.W., Wang, T.Y., Liu, S.J., Jones, K.C., Sweetman, A.J., Lu, Y.L., 2013. Industrial source identification and emission estimation of perfluorooctane sulfonate in China. Environ. Int. 52, 1-8.

Yang, L.P., Zhu, L.Y., Liu, Z.T., 2011. Occurrence and partition of perfluorinated compounds in water and sediment from Liao River and Taihu Lake, China. Chemosphere 83, 806-814.

Yao, Q.Z., Yu, Z.G., Wang, T., Chen, H.T., Mi, T.Z., 2009. Effect of the first watersediment regulation on the variations of dissolved inorganic nutrients' concentrations and fluxes in the lower main channel of the Yellow River. Environ. Sci. 30 (12), 3534-3540.

Yoo, H., Kannan, K., Kim, S.K., Lee, K.T., Newsted, J.L., Giesy, J.P., 2008. Perfluoroalkyl acids in the egg yolk of birds from Lake Shihwa, Korea. Environ. Sci. Technol. 42, 5821-5827.

You, C., Jia, C.X., Pan, G., 2010. Effect of salinity and sediment characteristics on the sorption and desorption of perfluorooctane sulfonate at sediment-water interface. Environ. Pollut. 158, 1343-1347.

Zhang, Y., Meng, W., Guo, C.S., Xu, J., Yu, T., Fan, W.H., Li, L., 2012. Determination and partitioning behavior of perfluoroalkyl carboxylic acids and perfluorooctanesulfonate in water and sediment from Dianchi Lake, China. Chemosphere 88, 1292-1299.

Zhao, L.X., Zhu, L.Y., Yang, L.P., Liu, Z.T., Zhang, Y.H., 2012. Distribution and desorption of perfluorinated compounds in fractionated sediments. Chemosphere 88, 1390-1397.

Zhao, Z., Tang, J., Xie, Z., Chen, Y., Pan, X., Zhong, G., Sturm, R., Zhang, G., Ebinghaus, R., 2013. Perfluoroalkyl acids (PFAAs) in riverine and coastal sediments of Laizhou Bay, North China. Sci. Total Environ. 447, 415-423.

Zheng, X.M., Liu, H.L., Shi, W., Wei, S., Giesy, J.P., Yu, X.X., 2012. Effects of pefluorinated compounds on development of zebra fish embryos. Environ. Sci. Pollut. Res. 19, 2498-2505.

Zushi, Y., Tamada, M., Kanai, Y., Masunaga, S., 2010. Time trends of perfluorinated compounds from the sediment core of Tokyo Bay, Japan (1950s-2004). Environ. Pollut. 158, 756-763. 